\title{
Competências profissionais de enfermeiros e sua gestão em um hospital particular
}

\author{
Professional competences of nurses and its management in a private hospital \\ Competencias profesionales de enfermeras y su gestión en un hospital privado
}

\section{Kely César Martins Paiva', Welinton Jesus Santos Junior"}

' Faculdade Novos Horizontes, Programa de Mestrado Acadêmico em Administração. Belo Horizonte-MG, Brasil. "Faculdade Novos Horizontes, Programa de Mestrado Acadêmico em Administração (Mestrando). Horizonte-MG, Brasil.

Submissão: 17-03-2011 Aprovação: 24-01-2013

\section{RESUMO}

O objetivo desta pesquisa foi analisar como se encontram configuradas e são geridas as competências profissionais de enfermeiros de um hospital particular (Belo Horizonte-MG), na percepção deles próprios. Foi realizado um estudo de caso descritivo, com abordagem qualitativa. Os dados coletados por meio de 15 entrevistas, incluindo-se a aplicação de uma técnica projetiva, foram submetidos à análise de conteúdo. A conjugação de conhecimentos práticos e teóricos e o cuidado para com o paciente foram as principais competências mencionadas pelos sujeitos, as quais são externalizadas de vários modos e geridas prioritariamente pelos próprios sujeitos. Diante dos dados e das limitações do estudo, foram realizadas sugestões para pesquisas futuras e para os atores sociais envolvidos.

Descritores: Competência Profissional; Enfermagem; Recursos Humanos de Enfermagem no Hospital.

\section{ABSTRACT}

The objective of this research was to analyze how the professional competences of nurses of a private hospital (Belo HorizonteMG) are configured and managed in their own perception. A descriptive case study was performed with a qualitative approach. The data from 15 interviews, including the application of a projective technique, were subjected to content analysis. The combination of practical and theoretical knowledge and the care for the patient were the core competences listed by the subjects, which are outsourced in various ways and managed primarily by themselves. Face the data and the limitations of the study, suggestions have been outlined for future research and for the actors involved.

Key words: Professional Competence; Nursing; Nursing Staff, Hospital.

\section{RESUMEN}

El objeto de esa pesquisa fue analizar como se encuentran configuradas y son gerenciadas las competencias profesionales de enfermeros de un hospital particular (Belo Horizonte-MG), en sus propias percepciones. Fue realizado un estudio de caso descriptivo, con enfoque cualitativo. Los datos recogidos en 15 entrevistas, incluyendo la aplicación de una técnica proyectiva, fueron sometidos a un análisis de contenido. La conjugación de conocimientos prácticos y teóricos y el cuidado para con el paciente fueron las principales competencias aludidas por los sujetos, las cuales son expuestas de varias maneras y gerenciadas de modo prioritario por los propios sujetos. Frente a los datos e las limitaciones del estudio, fueron realizadas sugestiones para pesquisas futuras y para los actores sociales envueltos.

Palabras clave: Competencia Profesional; Enfermería; Personal de Enfermería en Hospital. 


\section{INTRODUÇÃO}

Em virtude de várias mudanças que vêm ocorrendo no mundo e no Brasil, nas diversas esferas da vida humana, inclusive no campo do trabalho, tem-se ampliado a discussão sobre as competências profissionais e sua gestão dentro e fora das organizações. No campo específico da enfermagem, a gestão de competências é um assunto emergente, visando sinergia entre as equipes interdisciplinar e multiprofissional que compõem o quadro dos serviços de saúde ${ }^{(1)}$. Por mais qualificado seja o ensino acadêmico, ainda existem dúvidas sobre o limite da competência profissional de um enfermeiro e qual modelo regula os limites da competência de tais profissionais ${ }^{(1-2)}$.

Note-se que os padrões de trabalho correlacionam conhecimento e compreensão para obter desempenho efetivo ${ }^{(3)}$. Nesta perspectiva, os enfermeiros são entendidos como profissionais que recriam métodos, processos e instrumentos, adequando-os aos cenários onde elementos tais como autoconfiança, sensibilidade, pró-atividade e resistência, dentre outros, podem interferir e denotar competência; no entanto, estes fatores não são formalmente avaliados e nem normalizados para este fim $^{(3)}$. Complementa-se este raciocínio com o fato de que as pessoas possuem potenciais tanto para criar quanto para solucionar problemas, mas para que isto ocorra é preciso que tenham oportunidade e espaço para reflexão(4).

Quanto à distribuição do trabalho, a complexidade da enfermagem é explícita, pois "é uma atividade que dispende tempo e requer, da parte de quem a faz, conhecimentos relativos às necessidades da clientela, à dinâmica da unidade, às características da equipe de enfermagem e às leis trabalhistas"(5).

$\mathrm{O}$ contingente de profissionais de enfermagem vem crescendo nas diversas áreas de atuação desse profissional|(6). Enquanto estrutura organizacional complexa, o hospital vem tentando se adaptar às mudanças ambientais e uma das consequências desse processo é justamente a emergência da necessidade de novos perfis profissionais ${ }^{(7)}$, que incluem qualificação e competência profissional.

Note-se, ainda, o senso de urgência que permeia o trabalho ali realizado, o que implica, no plano organizacional, modelos de gestão peculiares e, no plano individual, vivências de situações limites constantes ${ }^{(8)}$, as quais exigem competência do profissional, em diversos sentidos: experiência clínica, maturidade, estabilidade emocional, agilidade e efetividade no processo de tomada de decisão ${ }^{(9)}$ além de funções de diversos outras atribuições como a assistência clínica, os próprios cuidados de enfermagem e a coordenação de pessoas e ações.

Diante dessa realidade, o objetivo geral da pesquisa desenvolvida foi analisar como se configuram e são geridas as competências profissionais de enfermeiros em um hospital particular mineiro, na percepção deles próprios. O Hospital particular onde se deu a pesquisa foi inaugurado em Belo Horizonte (MG) em 1968 por uma equipe de médicos. Atualmente, ocupa aproximadamente $12 \mathrm{mil} \mathrm{m}^{2}$, possui cerca de cem leitos, mais de 500 empregados e um corpo clínico que se distribui em 39 especialidades.

Esta pesquisa justifica-se com base nos seguintes argumentos: escassez de pesquisas que versam sobre o trabalho de enfermagem ${ }^{(10)}$ e sobre competência profissional do enfermei$\mathrm{ro}^{(1,10)}$; possibilidade de mudanças e melhorias nos processos envolvidos na gestão de pessoas a partir do conhecimento gerado $^{(4)} \mathrm{e}$, especificamente, no processo de gestão de competências dos enfermeiros no hospital abordado; importância dos hospitais como organizações fundamentais no contexto da saúde no Brasil(2), assim como os profissionais de enfermagem nesse contexto laboral ${ }^{(4)}$.

\section{REFERENCIAL TEÓRICO}

Historicamente, as competências foram estruturadas desde o princípio da organização do trabalho pautadas no binômio qualificação/profissão, mas não se refletem em componentes ou aspectos estáveis ${ }^{(11)}$. Pode-se conceber competência profissional como um "conjunto complexo e integrado de capacidades que as pessoas põem em jogo em diversas situações reais de trabalho para resolver os problemas com os quais se defrontam"(11). Relaciona-se, ainda, com uma disposição de se saber coordenar e/ou improvisar coordenações ${ }^{(12)}$, para a qual é necessário ter "domínio de conceitos, conhecimentos, métodos e ferramentas específicas para o exercício de uma determinada função" (1).

Considera-se que a competência vai além da qualificação, do potencial de ação: trata-se de uma mobilização real e produtiva de um conjunto de saberes de natureza diferenciada - formados por cinco componentes, a saber: intelectual; técnico-funcional; comportamental ou pessoal; ética e política - cujo resultado é reconhecido e valorizado tanto pelo próprio indivíduo como por terceiros ${ }^{(13)}$. Não é tão facilmente apreensível por outras pessoas, dado que diz respeito a um comportamento, um ato em si do indivíduo, cujo repasse não é simples ou imediato ${ }^{(13)}$.

Inicialmente contemplando quatro componentes(3), o modelo adaptado por Paiva e Melo(13) teve como acréscimo a componente política e suas descrições são as seguintes:

a. Intelectual ou Cognitiva: diz de saber teórico, de domínio de conhecimento formal;

b. Técnico ou funcional: refere-se à aplicação do conhecimento na ocupação do sujeito no processo produtivo e na organização, à habilidade de executar tarefas, produzindo resultados específicos na respectiva função;

c. Comportamental ou pessoal: relaciona-se à habilidades relacionais, à capacidade de adoção de comportamentos observáveis em situações de trabalho;

d. Ética ou valores: reflete adesão a códigos morais, sensibilidade para necessidades e valores de terceiros, cuidado na inserção e manutenção de neófitos na profissão;

e. Política: habilidade em jogos políticos e nas relações de poder inerentes às organizações, na manutenção do profissionalismo.

Pode-se perceber tais componentes por meio da ação, do comportamento efetivo do sujeito, chamado de "metacompetências na organização"(3), as quais se referem aos processos comunicativos, à criatividade, à capacidade de solução 
de problemas, à aprendizagem e ao autodesenvolvimento, à agilidade mental etc., frutos de um permanente processo de reflexão a partir das percepções do próprio indivíduo e de terceiros que lhe informam a respeito de sua atuação ${ }^{(3)}$.

Essa perspectiva considera ainda o caráter contextual das competências, já que as insere em um "contexto" e um "ambiente" de trabalho: a primeira refere-se a uma "situação particular na qual um profissional é requisitado a operar"; e o ambiente diz respeito a "condições físicas, culturais e sociais que envolvem um indivíduo no trabalho".

Assim, "não basta dispor de conhecimentos e de habilidade para agir com competência ou para elaborar estratégias eficazes de ação": é preciso que ocorra flexibilização e integração entre teoria e prática ${ }^{(12)}$. No caso da enfermagem, tais junções tomam contornos peculiares.

A enfermagem é o exercício regular de uma profissão que visa o cuidar da saúde debilitada de enfermos, vitimados por acidentes, incapacitados etc., assistindo quem precisa de cuidados especiais e, se necessário e prescrito, ministrando medicamentos, cuidando dos tratamentos diversos, zelando e respeitando a vida e a dignidade da pessoa ${ }^{(1)}$, caracterizando-se como uma prática social que visa à saúde ${ }^{(14)}$. Quem exerce atividades como enfermeiro tem de estar preparado para lidar com paradoxos, como vida e morte, dor e prazer ${ }^{(10)}$.

Assim, na enfermagem, o trabalho constitui um processo de intervenção que atua na saúde-doença, na dinâmica social e organização dos serviços; tanto na promoção, quanto na prevenção e/ou recuperação da saúde ${ }^{(10)}$, constituindo uma forma de atividade pautada na dimensão prática e de técnicas, de um lado, e, do outro, do saber administrativo, pois são dependentes no sistema de atendimento ${ }^{(14)}$.

Note-se, ainda, que "os papéis da equipe de enfermagem devem estar condizentes com a formação e a capacitação, claros e legitimados pela Lei do Exercício Profissional (...)"(4). No Brasil, a norma que regula o exercício da enfermagem é a Lei $n^{\circ} 7.498 / 1986^{(15)}$. Como complemento, a Lei explicita as restrições que normalmente são atribuídas à rotina dos profissionais em enfermagem, ou seja, do enfermeiro assistencial, do enfermeiro diarista, do técnico e do auxiliar de enfermagem.

No entanto, as aptidões ou qualidades pessoais de um enfermeiro são difíceis de serem expressas ou mensuradas: rigor, força de convicção, curiosidade de espírito, reatividade etc. (12). Tais aptidões são necessárias ao enfermeiro ${ }^{(4)}$, porém elas são de ordem particular, ou seja, podem variar também de acordo com a administração hospitalar ${ }^{(12)}$. Desta forma, deve-se considerar a gestão de competências profissionais um processo mais amplo que considere três $\operatorname{aspectos}^{(11)}$ :

a. O reconhecimento do indivíduo, através da competência ou competência profissional sem a necessidade de diplomas educacionais;

b. O gerenciamento dos sistemas educacionais de forma que possam desenvolver as competências profissionais;

c. O desenvolvimento contínuo das competências dos indivíduos ao longo de sua carreira, incluindo os desempregados.
Logo, a lógica da competência deve levar a uma revisão "das atividades particulares da gestão de pessoas. Tais atividades podem ser assim exemplificadas: descrição, análise e avaliação dos cargos; delineamento de carreiras; recrutamento e seleção; admissão e demissão; treinamento e desenvolvimento; avaliação funcional (desempenho, resultados e potencial); saúde e segurança ocupacional; relações com entidades de classe / sindicatos etc" ${ }^{\prime \prime 13)}$. Importante frisar que as iniciativas a este respeito devem partir tanto da gerência como do próprio empregado ${ }^{(13)}$.

Sob ótica semelhante, a gestão de competências pode ser compreendida como "todos os esforços individuais, coletivos, organizacionais e sociais, no sentido de formação e desenvolvimento de competências, que propiciam resultados de variadas naturezas, observáveis pelo indivíduo e por terceiros" (13). Desta maneira, cada ator social pode contribuir para o processo de formação e desenvolvimento de competências, considerando que:

a. As instituições de ensino são formadoras formais do profissional, ou seja, as universidades e suas políticas e práticas internas pedagógicas e de gestão de pessoas são responsáveis tanto pela formação e desenvolvimento das competências profissionais individuais como pela absorção desses sujeitos no mercado de trabalho;

b. O Estado legisla sobre a formação, por meio das Leis de Diretrizes Básicas da Educação e pareceres do Conselho Nacional de Educação;

c. As organizações onde os profissionais trabalham, por meio de suas políticas e práticas de gestão, contribuem para a formação contínua e contextualizada do profissional;

d. As instituições de interesse coletivo (associações e conselhos profissionais, sindicatos etc.) regulam a atuação do profissional e o sindicato das categorias profissionais envolvidas.

Desse modo, o modelo conceitual adotado para fins da pesquisa aqui apresentada foi o de Paiva e Melo ${ }^{(13)}$, ilustrado a seguir:

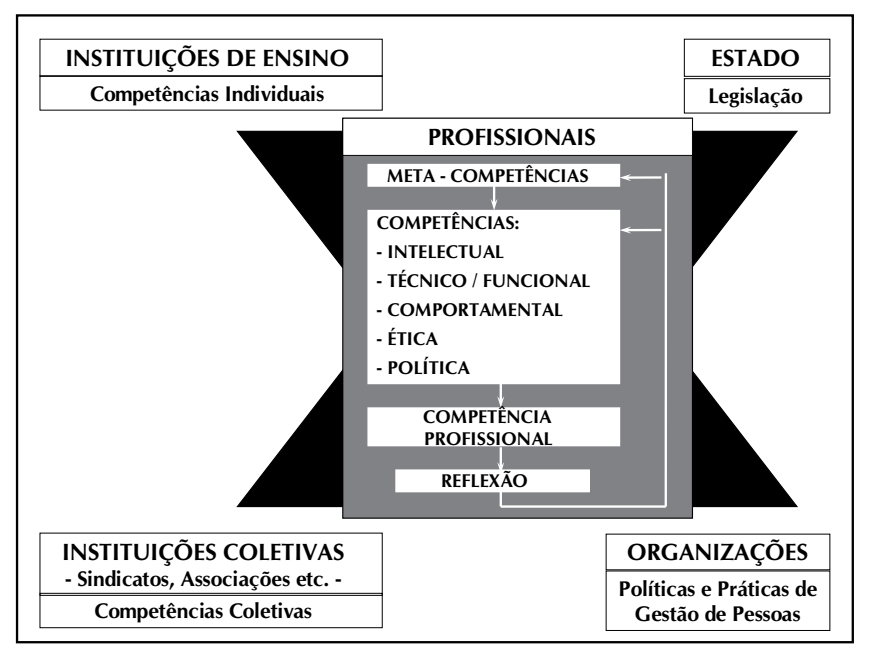

Figura 1 - Modelo Teórico-conceitual de Gestão de Competências, segundo Paiva e Melo ${ }^{(13)}$ 
Assim, sendo, a gestão de competências profissionais articula-se num espaço mais amplo e manifesta-se nas ações dos sujeitos no ambiente de trabalho. No caso dos enfermeiros, tal espaço é permeado de dificuldades peculiares, considerando principalmente o contexto e a natureza das atividades sob sua responsabilidade, as quais usualmente geram insatisfação, sentimentos de frustração, impotência e insegurança ${ }^{(16)}$.

Com vistas ao desnudamento desse fenômeno em um hospital particular, foi realizada uma pesquisa nos moldes seguintes.

\section{MÉTODO}

O modelo que mais espelha esta pesquisa é a descritiva, de campo, com abordagem qualitativa, nos moldes de um estudo de caso $^{(17)}$. O principal instrumento de coleta de dados foi a entrevista. Seu roteiro foi estruturado e abrangeu também a aplicação de uma técnica projetiva de associação, com objetivo apreender outras percepções, como recomenda a literatu$\mathrm{ra}^{(13)}$. No quadro a seguir, seguem as figuras apresentadas aos entrevistados, utilizadas na análise dos dados:

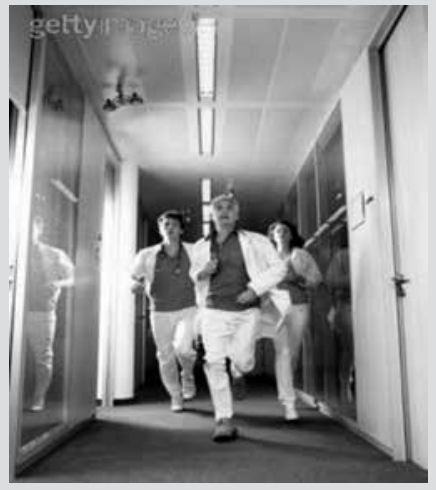

Figura I

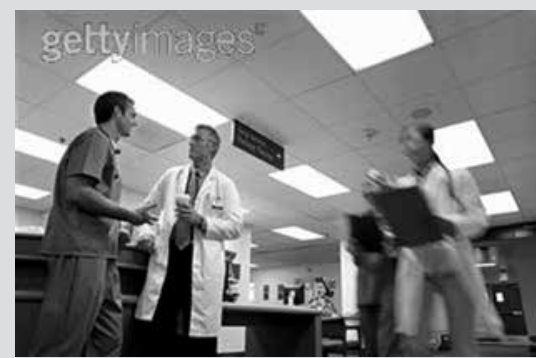

Figura IV

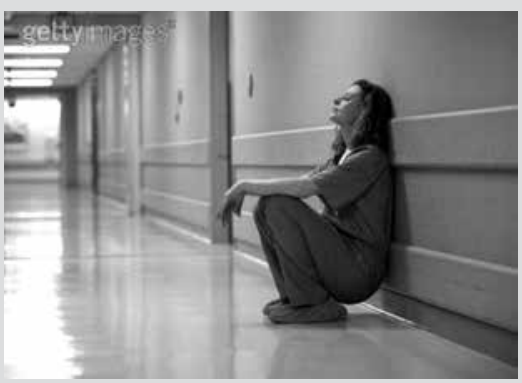

Figura VII

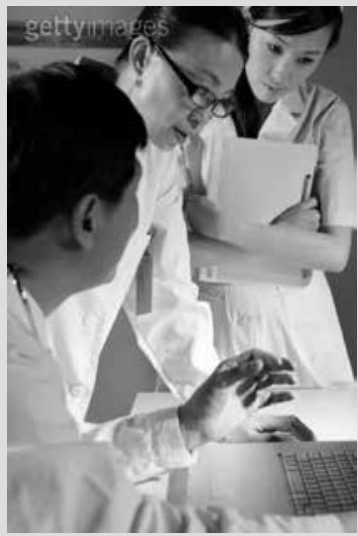

Figura II

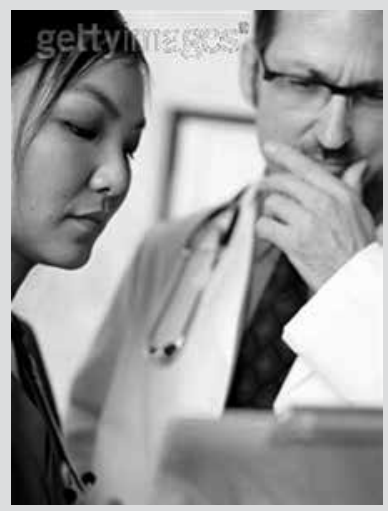

Figura V

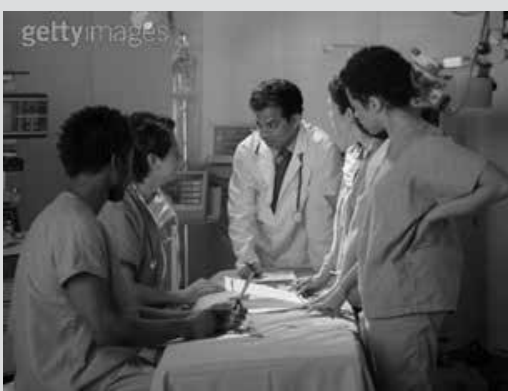

Figura III

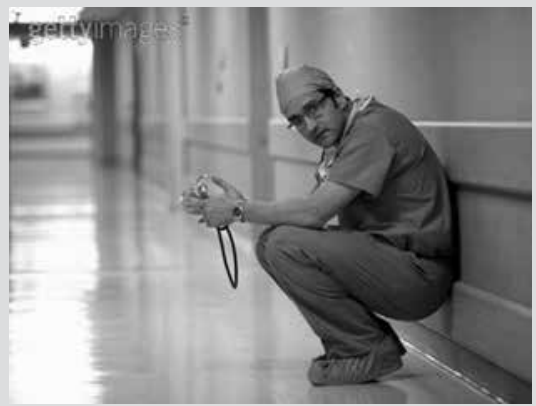

Figura VI

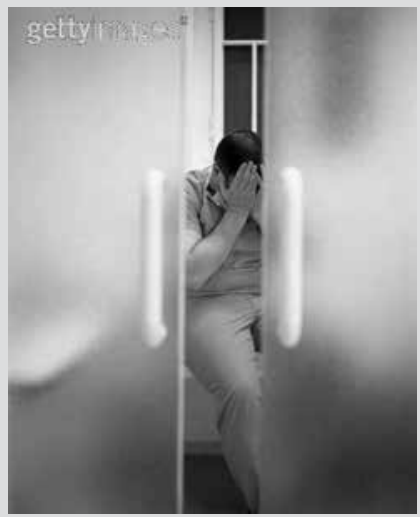

Figura VIII

Fonte: Gettyimages ${ }^{(18)}$

Quadro 1 - Figuras apresentadas aos entrevistados 
Esta utilização de instrumentos de coleta diferentes dentro de uma abordagem qualitativa caracteriza uma triangulação intramétodo ${ }^{(19)}$.

Após a aprovação da pesquisa pelo Comitê de Ética e Pesquisa do hospital (protocolo CAAE - 0012.0.230.230-09), foram realizadas 15 entrevistas, sendo que todas foram gravadas e, posteriormente, transcritas na íntegra, para permitir a análise dos dados. Cada entrevistado preencheu um formulário de identificação de modo a permitir traçar um perfil dos abordados e assinou um termo de consentimento livre e esclarecido. Assim sendo, o critério de inclusão dos informantes foi a acessibilidade ${ }^{(17)}$, dada pela disponibilidade em conceder a entrevista e a permissão da chefia; já os critérios de exclusão foram estar de férias, licença ou qualquer tipo de ausência do ambiente de trabalho durante a coleta, já que ela se deu no espaço onde as atividades dos informantes são desenvolvidas, considerando-se tal contexto peculiar e importante para o fenômeno em observação.

Os dados das entrevistas foram analisados de duas formas: estatística descritiva univariada para os dados do formulário de identificação; e análise de conteúdo para os dados da entrevista em si, incluindo os comentários dos entrevistados a respeito das figuras apresentadas na técnica projetiva. O tratamento dos dados foi disposto em três etapas: preparação dos dados (transcrição das entrevistas na íntegra e organização das respostas por perguntas); análise ou tabulação quantitativa (realização de síntese das respostas e frequência das mesmas); e análise temática (levantamento e síntese das temáticas consideradas importantes pelos entrevistados que não foram inicialmente explicitadas no roteiro). Esta forma de tratar e analisar os dados aderiu a recomendações da literatura ${ }^{(13)}$.

\section{APRESENTAÇÃO E ANÁLISE DOS DADOS}

Os dados demográficos dos 15 entrevistados podem ser sintetizados da seguinte forma: sexo - treze são do sexo feminino e dois do masculino; faixa etária - duas têm idade até 25 anos; seis entre 26 e 30 anos; quatro de idade de 31 a 35 anos; uma de 36 a 40 anos; uma de 41 a 45 anos; e uma de 46 a 50 anos; estado civil - oito são solteiros; seis casados; e uma divorciada; nível de escolaridade - dez deles possuem o curso superior completo; e cinco especialização; tempo de casa - dois estão há menos de 1 ano no hospital; oito de 1 a 5 anos; dois de 6 a 10 anos; um de 11 a 15 anos; e dois de 16 a 20 anos; cargo - dez são enfermeiros assistenciais; três ocupam cargo de coordenadores; um supervisor; e um gerente; tempo no cargo atual - três estão há menos de 1 ano no cargo atual; nove de 1 a 5 anos; dois de 6 a 10 anos; e uma de 16 a 20 anos; tempo de experiência total na enfermagem - um tem menos de 1 ano de experiência profissional; seis de 1 a 5 anos; seis de 6 a 10 anos; um de 16 a 20 anos; e um com mais de 20 anos de experiência.

O conceito de competência apreendido pelos entrevistados pauta-se em diversas componentes do modelo analítico $\operatorname{adotado}^{(13)}$, com predominância da funcional, voltada para a eficácia no trabalho, ou seja, atingir os fins a que o profissional se propõe no seu ambiente de trabalho (8 deles: E3, E4, E2, E5, E7, E9, E13, E14). Outra resposta recursiva refere-se à componente cognitiva, que se relaciona aos conhecimentos técnicos e teóricos necessários ao desempenho (7 deles: E11, E10, E12, E15, E3, E5, E8), mais voltados para qualificação ${ }^{(13)}$. Competência também foi verbalizada como envolvimento com a organização (5 deles: E1, E5, E6, E15, E8), que reflete as componentes ética e política ${ }^{(13)}$. A responsabilidade no trabalho também foi mencionada (2 deles: E5, E8), trazendo à tona as componentes funcional, ética e política ${ }^{(13)}$. Por fim, 2 entrevistados (E5, E8) falaram sobre a postura ética do profissional, o que está diretamente ligado à componente ética da competência ${ }^{(13)}$. Salientem-se os seguintes relatos ilustrativos, os quais demonstram a variedade de componentes para um exercício competente de uma profissão.

Eu acho que tem que ter várias coisas, que tem que estar envolvidas, ele tem que ser dedicado, tem que ter a responsabilidade do trabalho, tem que saber o horário de chegar, o horário de sair, tem que estar envolvido dentro da empresa e ter postura ética e ter o conhecimento técnico científico, que a gente precisa, no caso dos enfermeiros, precisa do conhecimento para estar no dia a dia com os pacientes (E5).

Um profissional competente num modo geral é aquele profissional que tem um conhecimento técnico aliado as questões gerenciais... exemplo: meu cargo, as questões gerenciais... pode ser num modo geral, né, conhecimento das ferramentas de gestão, conhecimento das competências mesmo de liderança, conhecimento técnico que eu não acredito que, principalmente na enfermagem, que dá pra você gerir sem ter o conhecimento... eu acho que o conhecimento é um aliado nosso para na gestão, por isso que muitas vezes o enfermeiro é o gestor exatamente por esse conhecimento (E12).

Especificamente sobre o sujeito competente na área de saúde, as respostas denotaram maior ênfase nas componentes funcional e cognitiva, tendo sido mencionado por sete dos entrevistados (E3, E8, E10, E11, E12 E13, E15) o ter "conhecimento prático e teórico". Além disso, o cuidar da pessoa, do ser humano e do seu bem-estar, que abriga componentes funcional, comportamental e ética ${ }^{(13)}$, também foi mencionado por 4 dos entrevistados (E1, E4, E7, E9). Outras respostas abordaram o cumprir o papel junto ao paciente pelo qual se está responsável (componentes funcional, ética, política ${ }^{(13)}$; entrevistado E7), o respeitar a ética profissional (componentes ética e política ${ }^{(13)}$; entrevistado E1) e o ter um bom relacionamento (componente comportamental $^{(13)}$; entrevistado E14). Tais respostas alinham-se à perspectiva do profissional de enfermagem caracterizado pelo cuidado a que se propõe à saúde do ser humano, de forma sistematizada, partindo do conjunto de conhecimento específico à prevenção, promoção e recuperação da saúde humana ${ }^{(4)}$.

Além disso, o preparo constante que qualifica o sujeito para o exercício da profissão também se fez presente nas falas, além da necessidade de foco quando dos processos formativos e da própria prática profissional como meio de desenvolver sua competência, denotando a face reflexiva de tal processo $^{(13)}$ : 
Eu procuro ler muito sobre a minha profissão, os assuntos que abrangem a minha profissão, eu leio muito, é assim que eu procuro ser (E3).

Na área da saúde, na nossa área, por exemplo, é muito ampla essa competência e a gente tem diversas áreas de atuação... Então eu acho que para você ser competente você tem que limitar um pouco a sua área de atuação... Somente na área da enfermagem é muito vasto, então, você não pode fazer de tudo um pouquinho, acho que você tem que fazer bem tendo noção de toda amplitude da sua profissão (E13).

Esta visão ampla da profissão está alinhada à percepção de que a prestação de serviços na área da saúde deve ser visualizada como um todo a fim seu trabalho impactar diretamente a relação com o paciente ${ }^{(1)}$. No entanto, quando perguntados especificamente sobre suas ações visando à formação e ao desenvolvimento de competências profissionais, notou-se uma centralidade no próprio sujeito, o que traz à tona o caráter individualizante em que o discurso da competência tem se circunscrito $^{(13)}$. Suas respostas versaram sobre: manter-se atualizado no mercado de trabalho (7 deles: E3, E8, E10, E11, E12, E14, E15); atender as expectativas da instituição (4 deles: E4, E5, E7, E10); ter eficácia no desempenho (3 deles: E4,, E5, E9); aperfeiçoar técnica e teoricamente (E1, E13); trabalhar em equipe (E6, E13); e respeitar a ética profissional (E1). Observou-se, assim, ênfase nos processos individuais e diretamente relacionados ao trabalho diário dos enfermeiros. Desse modo, o próprio trabalho é a principal fonte de oxigenação das competências desses profissionais, pautado em conhecimentos teóricos que os qualificam, fato considerado no modelo analítico adotado, por meio da abrangência ao ambiente e ao contexto de trabalho ${ }^{(13)}$. Os relatos que se seguem enriquecem a análise:

Acho que é estar buscando mais conhecimento, estar se atualizando no mercado de um modo geral e, na sua área específica, estar lendo, estudando acho que é mais ou menos em cima disto que a gente consegue estar alcançando, né... (E11).

Eu busco aperfeiçoamento não só na vida acadêmica, então, dentro das instituições, universidades, como aqui dentro do próprio hospital (E9).

O trabalho em equipe também foi mencionado quando da apresentação da Figura I para 8 dos entrevistados (E1, E2, E3, E4, E5, E7, E9, E14). Notem-se os comentários:

O pessoal correndo pra atender uma urgência, né, a equipe médica e enfermagem (E1).

São pessoas que estão correndo... eu interajo no meu setor, como um atendimento de urgência... os três estão tentando andar mais rápido para tentar atender o paciente de uma forma mais urgente (E9).
Além disso, a discussão de um caso clínico pela equipe também foi apontada por meio da aplicação da técnica projetiva: após visualizarem as Figuras II, III e IV, vários dos entrevistados (quatro deles na Figura II - E5, E10, E14, E15 -, oito deles na Figura III - E2, E4, E6, E8, E9, E10, E12, E14 - e três na Figura IV - E4, E7, E9) apontaram que esta forma de solucionar casos mais complexos também contribui para a formação de competências, principalmente pautadas nas componentes funcional e ética ${ }^{(13)}$. Observe-se o relato ilustrativo:

[Sobre a Figura IV] É... acho que é corrida de leito, né, parece, é o que a gente faz, os médicos discutem o caso clíni$\mathrm{CO}$, a gente corre os leitos, depois discute com eles... (E7).

O estudo de caso clínico não se encerra na prescrição da terapia para o paciente. Este procedimento usual no hospital - e que, ressalte-se, não foi verbalizado nas respostas das perguntas das entrevistas, mas apenas quando da aplicação da técnica projetiva - promove interação no interior da equipe e segurança nos membros, dado o compartilhamento da responsabilidade acerca do tratamento do caso.

Quando da visualização da Figura $V$, quatro enfermeiros $(E 1, E 5, E 9, E 14)$ se reportaram novamente à discussão de um caso e cinco deles (E13, E4, E6, E11, E12) indicaram as dúvidas que as pessoas têm durante o processo de tomada de decisão a respeito do caso do paciente. A fala de um entrevistado (E12) espelha tal análise:

A dúvida, a dificuldade que a gente enfrenta, às vezes, na hora de uma tomada de decisão, numa determinada situação, é sempre quando a gente tem com quem compartilhar, é mais fácil, te dá mais segurança nessas situações (E12).

Quanto à competência manifesta particularmente no hospital abordado (ou seja, os modos de externalizar a competência profissional no hospital abordado), as respostas mais recursivas dos enfermeiros mencionaram o trabalho em equipe (quatro deles: E8, E10, E11, E13), que reflete componentes funcional, comportamental, ética e política ${ }^{(13)}$, além da eficácia no trabalho (quatro deles: E4, E5, E7, E9), pautada substancialmente na componente funcional ${ }^{(13)}$. Além disso, foram relatados o buscar o bem estar dos pacientes (três deles: E2, E4, E9), o manter-se atualizado (3 deles: E3, E15, E1), o conhecer os processos do hospital (três deles: E13, E14, E15) e o utilizar as ferramentas de gestão (E12). Assim, percebe-se a mescla de responsabilidade, autonomia e trabalho em equipe ${ }^{(2)}$, necessária à efetividade do trabalho do enfermeiro, como resume o relato de um dos entrevistados:

Eu procuro executar tudo o que eu aprendi, de forma que possa agradar o todos os pacientes que eu atendo, e que eles dêem uma resposta positiva para o Hospital, para o pronto-socorro, no caso, que eu trabalho (E4).

Desse modo, a competência não se observa apenas no nível individual, mas também é possível perceber seus resultados no trabalho entre os pares, com subordinados, chefias e a própria organização, considerando-se seus diversos processos ${ }^{(13)}$. 
No entanto, diversas dificuldades são experimentadas pelos entrevistados para se manter competente, principalmente a falta de tempo que permita conciliar o trabalho em si com o desenvolvimento de suas competências (cinco deles: E1, E5, E7, E9, E13), o que explica, em parte, o fato de serem suas atividades laborais suas principais fontes de manutenção de suas competências. Além disso, outras dificuldades também foram apontadas pelos enfermeiros abordados, quais sejam: saber lidar com as pessoas (E2); dificuldades financeiras (E3); dificuldades com outros setores (E4); mudanças de escala (E8); relacionamento com a equipe (E10); falta de infraestrutura (E11); exercer mais de uma função (E12); falta de oportunidades para subir de cargo (E14); e limitações do cargo (E15). Estes dados espelham parte dos percalços envolvidos em tais processos. Tais dificuldades exprimem questões relacionadas ao próprio indivíduo na sua relação com seu trabalho e com a instituição, além de processos peculiares ao trabalho no âmbito hospitalar, como é o caso da sobrecarga do sistema e das escalas e turnos:

Eu acho que hoje tem muito em relação a tempo, né, porque para gente fazer (...), isso demanda certo tempo, e eu... Esse tempo que a gente tem que ter às vezes não é compatível com o que a empresa disponibiliza pra gente (E1).

Às vezes, a dificuldade que eu enfrento hoje é a dificuldade de escala, né, às vezes a gente tem uma escala um pouco apertada, se eu tiver uma demanda grande de pacientes - o meu setor é o CTI -, então, se tiver um número grande de pacientes, a minha escala é um pouco apertada, de funcionários e enfermeiros, então às vezes a gente acaba tendo um pouco de dificuldade para o ideal, o correto (E5).

A sobrecarga, o cansaço e a exaustão também foram mencionados quando da exibição das Figuras VI e VII, tendo sido esta percepção verbalizada por doze dos entrevistados (E1, E2, E3, E4, E5, E7, E8, E9, E10, E11, E12, E15). Os relatos apontam para momentos de descanso e reflexão:

O que vem primeiro na minha mente é "profissionais cansados", assim exaustos, desanimados... (E12).

Uma médica cansada (risos) é..., bom, depois de um dia inteiro de trabalho (...), cansada mesmo, refletindo como é que foi o dia, para poder conceber tudo (E7).

A aplicação da técnica projetiva apontou para outras dificuldades além da exaustão, também mencionada por três dos entrevistados (E1, E8, E14) quando da visualização da Figura VIII.

A maioria dos entrevistados (dez deles: E2, E3, E4, E5, E6, $\mathrm{E9}, \mathrm{E} 10, \mathrm{E} 11, \mathrm{E} 12, \mathrm{E} 15)$ reportou-se a sentimentos negativos experimentados pelo enfermeiro durante seu trabalho, como "desespero", "insatisfação", "tristeza", "desilusão", "angústia", "incerteza", "limite da capacidade", dentre outros.

Essa é pesada (risos)... Eu acho que é um momento de... desespero, assim, de insatisfação mesmo, foi alguma coisa que aconteceu que não deu certo, acredito (E3).
Lidar com tais sentimentos faz parte de um processo de aprendizagem e reflete o desenvolvimento de competências, o qual se inicia pela própria identificação das situações nas quais tal enfrentamento faz-se necessário. Nestas ocasiões, podem ser desenvolvidas competências pautadas em componentes comportamental, funcional, ética e política ${ }^{(13)}$.

Apesar das dificuldades no processo de manutenção de competências ${ }^{(13)}$, quando foi perguntado especificamente sobre as possíveis contribuições do hospital para o desenvolvimento dos enfermeiros, quase todos os entrevistados (quatorze deles: E1, E2, E3, E4, E5, E6, E7, E8, E9, E11, E12, E13, E14, E15) responderam positivamente, mencionando principalmente os seminários e cursos de capacitação oferecidos pela organização (dez deles: E2, E3, E4, E5, E7, E8, E9, E12, E13, E15). Além disso, 3 deles (E10, E13, E15) mencionaram a flexibilização de horários para estudos fora do ambiente hospitalar. Outros dois (E1, E12) discorreram sobre o investimento em recursos. Outras contribuições assinaladas foram o fornecimento de artigos do jornal do Conselho Regional de Enfermagem (COREN) (E6), o atendimento das necessidades do profissional (E11), o pagamento de transporte e inscrição em cursos (E13), a manutenção de um bom relacionamento entre os médicos (E14). Segundo o entrevistado E10, tais contribuições poderiam ser melhores, mas não entrou em detaIhes a esse respeito, indicando expectativas frustradas desse profissional em relação ao hospital. Além disso, investimentos em tecnologia de gestão foram rememorados por um entrevistado (E12) como algo que propicia ampliação no escopo de competências dos enfermeiros:

Como agora, principalmente, com esse investimento que o hospital está fazendo, comprou um software só de gestão, eles vão proporcionar pra gente treinamentos, então eu acho que isso já é investimento... (E12)

Apesar da filiação obrigatória ao conselho profissional, o Conselho Regional de Enfermagem, COREN, seis dos entrevistados (E7, E8, E9, E10, E11, E12) afirmaram não participar de suas atividades. Além disso, seis (E1, E4, E5, E6, E13, E14) mencionaram ações do Conselho no sentido de contribuir para seu desenvolvimento: buscando melhores condições de trabalho (E1), viabilizando estudos por meio do registro (E4), organizando congressos e cursos (E5), disponibilizando artigos no jornal e no site (E6 e E14) e dando orientações profissionais (E13).

Eu acho que o Coren poderia contribuir mais, mas eu participo pouco também, a minha participação poderia ser maior, porque ele também tem o congresso, tem seminários que ele vira e mexe estão oferecendo... desses eu nunca participei, não (E5).

Ele contribui (...) através dos artigos do jornal do Coren assim, só dessa forma, no geral não (E6).

Verifica-se um círculo vicioso na relação do enfermeiro com o Conselho, em que pouca participação leva a pouca legitimidade e esta, por sua vez, a pouca mobilização, não 
se verificando um sistema de cooperação de competências ${ }^{(12)}$, que tem impactos diretos na profissionalização da categoria.

Do mesmo modo, doze deles (E1, E2, E3, E4, E5, E6, E7, E8, E9, E11, E12, E13) também não participam ativamente do respectivo sindicato. Apenas um entrevistado (E10) percebe contribuições do mesmo, em termos de oferta de cursos, seminários e congressos, para manutenção de suas competências profissionais.

Assim sendo, a contribuição do hospital só foi explicitada quando perguntada diretamente, o que ratifica a percepção de maiores esforços individuais do que organizacionais ou mesmo coletivos e sociais, denotando fragilidades no processo de gestão de competências ${ }^{(13)}$, extremamente centrado no indivíduo.

Já os relacionamentos dos entrevistados com outros atores sociais parecem ser saudáveis e estar contribuindo para o desenvolvimento das componentes comportamental e política ${ }^{(13)}$ da competência profissional em diversos níveis. De modo geral, todos os relacionamentos foram caracterizados de forma positiva por todos os entrevistados:

$\checkmark$ Com seus colegas de profissão, gerando impactos no atendimento do paciente:

Bom, a gente tem uma boa convivência, a gente tenta conviver bem pra poder prestar um serviço melhor, porque se a gente não conviver bem eu acho que... falta até para o paciente (E4).

$\checkmark$ Com outros membros da equipe multidisciplinar:

Eu acho que, acima de tudo, existe um respeito, (...) principalmente a gente que trabalha, (...) faz parte de uma equipe multidisciplinar então eu acredito que é muito bom (E15).

$\checkmark$ Com subordinados, apesar de conflitos e resistências que vem sendo gerenciados:

Alguns subordinados... é mais difícil lidar, por causa de resistência, mas, de qualquer maneira, a gente tenta colocar tudo claro (E7).

$\checkmark$ Com familiares e pacientes, repercutindo positivamente na assistência prestada, já que o enfermeiro tem se colocado no lugar deles (E6) e os tratado de forma humana e com respeito (E7 e E9).

Além disso, a maior parte dos entrevistados (doze deles: E1, E2, E4, E5, E7, E8, E9, E10, E11, E13, E14, E15) afirmou que as atividades de outros profissionais contribuem para a efetividade do trabalho exercido por eles próprios, denotando o caráter contextual e relacional da competência profissional ${ }^{(13)}$ na realidade observada.

Manutenção, serviço de hotelaria, copa, é... acho que (...) os outros setores, blocos cirúrgicos que me mandam os pacientes, que eu recebo os pacientes deles, a unidade de internação que eu mando os meus pacientes para eles, o pessoal da portaria que (...) isola para gente o serviço, os horários, os familiares que vão entrar e sair, a gente acaba pegando um pouquinho de cada um (E5).

O reconhecimento da competência do profissional também é abordada no modelo analítico adotado ${ }^{(13)}$, já que é informada por terceiros e faz com que, a partir da reflexão do sujeito, este repense e revise suas componentes e externalize-as por meio de ações que vão gerar resultados legítimos para os envolvidos, denotando sua base em um sistema de valores mais amplo ${ }^{(12)}$. Nesse sentido, manifestações de legitimação são percebidas pelos entrevistados, já que, quando perguntados sobre como os demais colegas os percebem dentro do hospital, as respostas de treze deles (E1, E2, E3, E4, E5, E7, E8, E9, E10, E11, E12, E13, E15) foram positivas. Segundo eles, os demais profissionais percebem seu bom trabalho (E5, E8, E9), percebem pelo retorno do seu trabalho e sua convivência no hospital (E11, E12), eles são valorizados pela instituição e pelos colegas (E1, E13), ajudam de alguma forma (E3), acham imprescindível a profissão de enfermeiro (E4), julgam-no competente (E7), percebem que o enfermeiro é sobrecarregado no hospital (E10), assim como o dinamismo do setor de enfermagem (E15), por fim, eles se sentem respeitados (E2). O comentário de um entrevistado (E8) denota transparência no relacionamento com os demais membros e como isso pode facilitar o feedback que contribui diretamente no processo de gestão de competências no nível individual e coletivo ${ }^{(13)}$ :

[10 segundos de silêncio] Eu acho que percebem como um bom trabalho porque, se não fosse, eu acho que já teriam reclamado alguma coisa para a gente tentar melhorar (E8).

No entanto, E6 e E14 manifestaram-se de modo contrário, explicitando dificuldades pessoais com outros colegas (E6) e a percepção de que nem todos reconhecem o trabalho do enfermeiro no hospital (E14). Observe-se o relato de um deles, relacionado à perspectiva de carreira na instituição:

Tem gente aqui que tem vontade de ser [enfermeiro], mas não tem vontade de melhorar, ou seja, quer ser, mas não procura melhorar, aí fica aquele clima meio ruim, mas eu já superei isso, no começo era pior, hoje em dia não, hoje em dia eu encaro por que é uma profissão, é o que eu escolhi e é o que eu vou fazer (E6).

Diante dos dados apresentados e analisados, considerações finais foram tecidas.

\section{CONSIDERAÇÕES FINAIS}

O objetivo geral deste estudo foi analisar como se configuram e são geridas as competências profissionais de enfermeiros em um hospital particular mineiro, segundo a percepção deles próprios. Visando aprofundamento conceitual e delimitação do modelo analítico adotado ${ }^{(13)}$, o referencial teórico tratou de competências profissionais e de sua gestão, e especificidades observadas na enfermagem no contexto hospitalar. 
A pesquisa descritiva realizada foi de caráter qualitativo, nos moldes de um estudo de caso. Os dados foram coletados por meio de entrevistas junto a 15 enfermeiros e analisados conforme técnica de análise de conteúdo.

Foi observado que as principais competências profissionais consideradas pelas enfermeiras foram a conjugação de conhecimentos práticos e teóricos (ênfase nas componentes cognitiva e funcional da competência) e o cuidado para com o paciente (ênfase nas componentes funcional, comportamental e ética da competência), as quais são externalizadas por meio do trabalho em equipe, dos resultados apresentados (eficácia no trabalho), da permanente atenção ao bem estar dos pacientes e à atualização, inclusive quanto aos processos do hospital, que vem investindo em tecnologia de gestão.

Notou-se também que as ações voltadas para a gestão de competências profissionais são vistas como de responsabilidade do próprio enfermeiro, que vive uma realidade exaustiva e angustiante - muito enfatizada quando da aplicação da técnica projetiva ao final da entrevista, dada a sobrecarga de trabalho que muitas vezes dificulta tal processo. As iniciativas do hospital nesse sentido foram citadas apenas quando perguntadas diretamente, principalmente as de cunho formal.

A técnica projetiva também trouxe à tona as atividades relacionadas às discussões de casos clínicos como uma das formas usuais de desenvolver competências na instituição. De modo mais sutil, os jogos políticos, inerentes a qualquer tipo de organização, também foram alvo da atenção de parte dos entrevistados, principalmente em relação aos seus próprios subordinados - os outros membros da equipe de enfermagem - e aos médicos, vistos como figuras centrais nos processos de trabalho dentro do hospital, porém com um distanciamento cujas razões carecem de aprofundamento em futuras pesquisas, conforme já observado em outros estudos $^{(6,20)}$, que também têm apontado para a necessidade de conjugação de temas para uma melhor compreensão da realidade do enfermeiro, em especial no contexto hospitalar ${ }^{(20)}$.

Diante dos dados analisados e da limitação de se ter realizado o estudo em apenas um hospital privado, sugere-se a ampliação da pesquisa para outros hospitais, inclusive públicos, e para outras categorias profissionais que compõem a equipe multidisciplinar na assistência à saúde, pois os achados apresentados evidenciaram o caráter contextual e também relacional das competências profissionais, o que precisa ser entendido como de fato acontece: um fenômeno, uma prática social complexa e que envolve diversos atores sociais ${ }^{(11,13)}$.

Quanto ao hospital e aos enfermeiros, revisar as políticas de gestão de pessoas concretiza-se como opção para alavancar a formação e o desenvolvimento de competências, ou seja, sua gestão em diversos níveis, principalmente com incentivos mais amplos relacionados tanto a meios formais como informais de aprendizagem, além da institucionalização de processos relacionados às discussões de casos clínicos de modo a tornar essa atividade mais extensa e democrática, dado seu potencial de contribuição ainda não explorado.

\section{REFERÊNCIAS}

1. Marx LC. Competências da enfermagem: sedimentadas no sistema primary nursing. Petrópolis, RJ: EPUB; 2006.

2. Felli VEA, Peduzzi M. O trabalho gerencial em enfermagem. In: Kurcgant $\mathrm{P}$, coordenadora. Gerenciamento em Enfermagem. Rio de Janeiro: Guanabara Koogan; 2005. p. 1-13.

3. Cheetham G, Chivers GT. Holistic Model of Professional Competence. Journal of European Industrial Training 1998; 20(5): 5-6.

4. Yoshimoto, MS, Campos RD, Lima AR, Condori, RCC. Comunicação como competência para o processo educativo das equipes de enfermagem. In: Cunha KC, coordenadora. Gerenciamento na enfermagem: novas práticas e competências. São Paulo: Martinari; 2005. p. 69-86.

5. Massarollo MCKB. Escalas de distribuição de pessoal de enfermagem. In: Kurcgant P. Administração em Enfermagem. São Paulo: EPU; 1995. p. 109-16.

6. Avelar VLLM, Paiva KCM. Configuração identitária de enfermeiros de um serviço de atendimento móvel de urgência. Rev Bras Enferm 2010;63(6):1010-8.

7. Arone EM, Cunha ICKO. Avaliação tecnológica como competência do enfermeiro: reflexões e pressupostos no cenário da ciência e tecnologia. Rev Bras Enferm 2006;59(4):18-26.

8. Carreteiro TCO, Barros V. Clínicas do trabalho: contribuições da psicossociologia no Brasil. In: Bendassolli PF, Soboll LAP, organizadores. Clínicas do Trabalho. São Paulo: Atlas; 2011. p. 208-26.

9. Rosa C, Carlotto MS. Síndrome de burnout e satisfação no trabalho em profissionais de uma instituição hospitalar. Rev Soc Bras Psicol Hosp 2005;8(2):1-15.

10. Felli VEA, Tronchin DMR. A qualidade de vida no trabaIho e a saúde do trabalhador de enfermagem. In: Kurcgant P, coordenadora. Gerenciamento em Enfermagem. Rio de Janeiro: Guanabara Koogan; 2005. p. 89-107.

11. Ramos MN. A pedagogia das competências: autonomia ou adaptação? São Paulo: Cortez; 2002.

12. Boterf GL. Desenvolvendo a Competência dos Profissionais. Porto Alegre: Artmed; 2003.

13. Paiva KCM, Melo MCOL. Competências, gestão de competências e profissões: perspectivas de pesquisas. Rev Adm Contemp 2008;12(2):339-68.

14. Gomes ELR, Anselmi ML, Mishima SM, Villa TCS, Pinto 
IC, Almeida MCP. Dimensão histórica da gênese e incorporação do saber administrativo na enfermagem. In: Almeida MCP, Rocha SMM, organizadores. O trabalho de enfermagem. São Paulo: Cortez; 1997. p. 229-50

15. Brasil. Lei $n^{\circ} 7.498$ de 25 de junho de 1986. Dispõe sobre a regulamentação do exercício da enfermagem e dá outras providências. Diário Oficial da União, 26 jun 1986.

16. Jorge MSB, Freitas CHA, Nóbrega MFB, Queiroz MVO. Gerenciamento em enfermagem: um olhar crítico sobre o conhecimento produzido em periódicos brasileiros
(2000-2004). Rev Bras Enferm 2007; 60(1):81-6.

17. Vergara SC. Projetos e relatórios de pesquisa em Administração. São Paulo: Atlas; 2009.

18. Gettyimages [homepage na internet]. [acesso em $04 \mathrm{dez}$ 2009]. Disponível em: <http://www.gettyimages.com > .

19. Jick TD. Mixing qualitative and quantitative methods: triangulation in action. Adm Sci Q 1979;24(4): 602-11.

20. Dias, HC, Paiva KCM. Competências do enfermeiro: estudo em um hospital privado. Rev Bras Enferm 2011,64(3):511-20. 